as it was made after they had been warned of the dangers of phenacetin.

Dr. Kincaid-Smith also states that in Australia paracetamol was substituted for phenacetin in the A.P.C. mixtures in the National Health Service listing about eight years ago, but nevertheless analgesic nephropathy is still very cornmon. This statement suggests either that Dr. KincaidSmith thinks that paracetamol is as destructive as phenacetin, a suggestion which we believe is probably correct, though in Great Britain the evidence is only just beginning to appear, or it suggests that Dr. Kincaid-Smith thinks that beause phenacetin was removed from the National Health Service listing it therefore should have disappeared from the Australian scene. One gathers however that this is far from the truth. For instance, Purnell and Burry ${ }^{2}$ in a survey in a country town in Queensland found that the average weekly phenacetin consumption for a person over 15 years old was $1.845 \mathrm{~g}$. Only $37 \%$ of the phenacetin sold came from chemists and only a very small proportion of this was sold via prescriptions. They concluded that "the recent removal of phenacetin-containing drugs from the free-list of phenacetin benefits in Australia is unlikely to have any appreciable eff :ct ucon the consumption of phenacetincontaining analgesics by the community". The situation seems to be analogous to our own. We found that though phenacetin has now heen removed from mo:t proprietary preparations this could have little effect on the total ingestion of phenacetin as fourfifths of the phenacetin ingested is in the form of B.P. and B.P.C. preparations.

We wo:ld submit that the case against phenacetin is formidable, and we would once more plead that it should be available only on a doctor's prescription.-We are, etc.,

H. E. DE WARD TNER

Department of Medicine

Charing Cross Hospital

Medical School,

Fulham Hospitat,

ondon W.

Nanra, R. S., Fairley, K. F., and Kincaid-Smith, P. Australasian Annals of Medicine, 1970, 19, 195. Australia, 1967, 2, 389 .

\section{Diabet:c Ketoacidosis and Influenza}

Sir, - I was interested in the communication by Dr. P. J. Watkins and others (10 October p. 89) about the marked incidence of hypok laemia in diabetic ketoacidosis provoked by influenzal illness.

I would like to suggest one possible mechnaism for potassium loss in such instances-namely, through the nasal secretions, if there is rhinorrhoea and or pneumonia. Very lit le information is available in the literature regarding the nature of the nasal mucus, mainly because it normally exists only as an extremely thin laver on the mucosal surface. ${ }^{1}$ Ingelstedt and Ivstam injected of fluorescin intravenously and found none in the nasal secretion They concluded that the mucin gland alone were the source of the normal nasa mucus." However, there is a general agreement that in inflammatory conditions, it consists to a large extent of an exu-tate."

Information regarding the electrolyte concentration in the normal nasal secretion is likewise virtually non-existent. Proetz stated that the constituents of the nasal mucus are generally 2.5 to $3 \%$ mucin, $1-2 \%$ salts, and $95-97 \%$ water. ${ }^{3}$ Potter et al.,' reporting on the analysis of whole pulmonary secretion in laryngectomized patients, obtained a potassium concentration of $13.2 \pm 5.4 \mathrm{mEq}$ per gram of secretion. Two years ago I had the chance to analyse a sample of my nasal secretion, while suffering from an attack of coryza. Using the atomic absorption method the potassium concentration in that sample was $26 \mathrm{mEq} / 1$.

The volume of mucus secreted per day through the nasal mucosa is estimated to be more than a litre.' With rhinorrhoea this volume is obviously multiplied many times, and if we add the volume of the whole pulmonary secretion produced in pneumonia, as was the case in several of Dr. Watkins's patients, the net loss of potassium may be significant, especially if the dietary intake is low.-I am, etc.

RiDHA HAJJAR

Wadsworth Veterans Administration Hospital

Los Angeles, California, U.S.A.

Proctor, D. F., in Handbook of Physiology, Section 3, Respi a:ion, 1. n 309. W'ashington,
American Physiological Society, 1964 .

Ingelstedt, S., and Irstam, B., Acta Otolaryn logica, 1949, 37, 446.

Proetz, A. W., Essays on the Applied Phystology of the Nose, $2 \mathrm{n} 1$ edn., St. Louis, Annals Potter, J. L., Maith ws.

Spector, S., Annals of the New York, J., and of Sciences, 1963, 166, 692 .

\section{Exposure Treatment for Phobias}

SIR,-We were most interested to read the article by Dr. J. P. Watson and others (2 January, p. 13). It seems likely that the authors' findings that treatment with prolonged exposure produced better results in less time than other treatments so far reported for chronic phobic disorders will receive wite acceptance and will arouse a great deal of enthusiasm. This, we suggest, would be unfortunate, since whether or not prolonged exposure is in fact dramatically effective in treatment of chronic phobic disorders is certainly not established by the study under discussion.

The study is uncontrolled, the number of patients treated is small, and the selertion is biased. As long ago as 1957, Foulds ${ }^{1}$ reported that authors claimed success in psychiatric treatment in $85 \%$ of uncontrolled studies compared to $19^{\circ} \%$ of studies in which controls were used; apparently, the moral has yet to be learnt.

The results of this study cannot be accepted valid ant conclusive as there are no parameters available to determine the effect of passage of time. suggestion, placebo effects, bias, and overemthusiasm-which is so of ten associated with a new type of treatment. At the same time a retrospective comparicon can not be made hetween the results of this inappropriately conducted trial and patients treated previously, as in this case it cannot be assumed that groups are comparable. Dr. Watson and colleagues' results would have been more conclusive and convincing if they had eliminated these shortcomings by the basic procedure of employing controls and random allocation between groups.

The flooding and prolonged exposure method are attractive because of their sim- plicity and their satisfactory administration by novices, whereas desensitization requires skill and practice to be effectively performed. As these methods will be employed more frequently, one should be aware of certain aspects of considerable theoretical and practical importance which has not been considered in clinical evaluation. Duration of the treatment session and, closely related to this, the point at which the treatment session can be terminated, are important because theoretically one may expect that premature termination of a treatment session (that is, when the patient is still at an exceedingly high level of arousal) may result in an exacerbation rather than a reduction in anxiety. This possibility is raised both by Eysenck's" theory of the incubation of fear responses and can also be deduced from the maximal habituation theory proposed by Lader and Mathews's ${ }^{3}$ and some experimental evidence for supporting these sensitizing interpretations is accumulating (Fazio'). The other factors which determine the efficacy of response prevention include the extent to which responses have been overtrained, the amount of response prevention given, the intensity of the fear underlying the avoidance response, and the necessity for the sub;ect to cease fear behaviour and engage in relaxation behaviour during response prevention if subsequent rapid extinction of avoidance response was to occur (Baum"). To enhance the efficacy of response prevention and overcome the problem of exacerbation of anxiety, the use of short-acting barbiturate (thiopentone) in doses small enough to produce relaxation has been suggested (Hussain ${ }^{6}{ }^{7}$ ). Thanks to this pharmacological aid the anxious neurotic has less difficulty exploring and discussing his fears because of the relaxed state produced by the barbiturates and has protection against the more disagree?ble manifestation of anxiety. Its use causes reduction in critical sense and an enhencement of rapport. Aggressive feelings which would terrify the individual in his normal state can be expressed without excessive anxiety and emo:ional experience can be relieved. In this state, the patient accepts suggestions more readily, can visualize the versions of the situations suggested more realistically, and experiences the appropriate emotional responses. It has the additional advantage of obviating the panic reaction due to the patient's fear of death in the course of therapy. As well, the use of thiopentone abolishes the possibility of exacerbation of anxiety to premature termination of the treatment

In short, treatment with response prevention (flooding, exposure) which is arousing a great deal of enthusiasm is still in the experimental stages and its mode of action controversial; and as there appears to be some danger associated with its uce one should be cautious against the uncritical acceptance of the technique and reports of its successes and failures.-We are, etc.,

M. Z. HuSSAIN

Psychiatric Drpartment,

D partment of Public Health,

Province of Saskatch cwan

1 Foulds, G. A., Journal of Mental Science, 1958

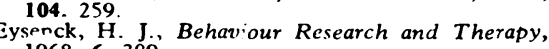
Eysenck, H. J., Behaviour Research and Therapy,
$1958,6.309$. Research and Therapy, 1968, 6, 411 . 
- Fazio, A. F., Fournal of Abnormal Psychology, $1970,76,211$.

23, M., Canadian Fournal of Psychology, 1969

6 23, 1. M. Z., Canadian Medical Association fournal, 1970, 103, 768

1971 , in press.

\section{Alopecia and Levodapa}

SIR,-The side effects of levodopa administration are well known (30 January, p. 267). We report here two cases in which alopecia developed during treatment with levodopa.

A 54-year-old woman with idiopathic Parkinson's disease of long standing was treated in November, 1970 with levodopa. The dose was increased to $3 \mathrm{~g}$ daily over the next month, with considerable improvement, but after a further three weeks she developed choreiform movements, mental agitation, and severe flushing of the face and neck. On stopping treatment these sideeffects disappeared within three days. Levodopa was then given in a dose of $1 \mathrm{~g}$ daily with clinical improvement. Now, however, three months after first taking levodopa, she developed a severe diffuse alopecia. No other cause for this was found. Haemoglobin, leucocyte count, and blood film were normal and serum thyroxine iodine was $5.8 \mathrm{mg} / 100$ $\mathrm{ml}$ with a free thyroxine index of 6.4

The second patient was a 63-year-old woman with a 20-year history of idiopathic Parkinson's disease. In November 1970 she was treated with levodopa with considerable benefit. The dose was gradually increased to $2.5 \mathrm{~g}$ daily and maintained at this level when she complained of mild nausea. Six weeks after starting this treatment she complained of hair loss and moderately severe diffuse alopecia was confirmed. Again there was no apparent cause for the alopecia. She had no clinical evidence of hypothyroidism, and serum thyroxine iodine was $5.5 \mathrm{mg} / 100$ $\mathrm{ml}$ with a free thyroxine index of 6.8 . Haemoglobin, leucocyte count, and blood film were normal.

Both patients preferred to continue with levodopa although it was explained that their hair loss might be associated with this treatment. In both cases the partial alopecia persists.

B:tween them these cases demonstrated the well-known side effects of nausea, mental agitation, and involuntary choreiform movements. As far as we know severe flushing of the face and alopecia have not been described with levodopa administration. These symptoms may be no more than coincidental to the treatment, but we would be interested to know if a similar phenomenon has been noted by others.-We are, etc.,

A. MarshaLI

Royal Infirmary, Bristol

\section{J. Williams}

\section{Amino-acids in Fetal Fluids}

SIR,-I read with interest the paper by Dr. F. Cockburn and others (26 September, p. 747). Several comments might be made. The techniques of collection, storage, and speed of quantitation are such that their data are above question. However, their final conclusion that "Inborn errors which result in altered fetal urinary amino-acid excretion might thus be identified in utero" is quite doubtful. If the offending amino-acids are metabolizable by the mother fetal homeo- stasis will be maintained, and it is highly unlikely that amniotic fluid will reflect any aberration. Our data from paired amniotic fluid and fetal urine at term suggest that very little of the amino-acid composition of amniotic fluid is derived from urine and in an affected fetus the branched chain aminoacid concentrations of amniotic fluid from a patient with proved maple syrup urine disease were normal. 1

The reason that $I$ raise this point is to caution clinicians who are diagnosing potential amino-acid defects prenatally. Other methods of prenatal diagnosis such as direct enzyme analysis, quantitation of a nonmetabolizable product, or analysis of cultured cells has been proved of value. By looking at amniotic fluid amino-acid concentration false negative results will be given to mothers at a time when termination of pregnancy could be accomplished if that particular course of therapy was desired. I am, etc.,

\section{Grant MORROW}

\section{Department of Pediatrics,}

Hospital of the University of Pennsylvania,

'Neill, R. T., Morrow, G., Hammel, D., Auerbach in press.

\section{Laparoscopy Hazard}

SIR,-With reference to the laparoscopy hazard reported by $\mathrm{Mr}$. Humphrey Arthure (21 November, p. 492), I should like to make a few comments.

Laparoscopy is an extremely safe procedure, and if the methods used for creation of the pneumoperitoneum are simple there is no risk of cardiac arrest, air emboli, or shock from "impaired respiration or circulation". I follow the simple method of air insufflation with a blood-pressure bulb, and stop when the abdomen is distended sufficiently for the creation of a space between the viscera and anterior-peritoneum or when the patient complains of discomfort. We have never found it necessary to use more complicated methods or manometers, and the only complication that we have found related to the pneumoperitoneum is on decompression following evacuation of large amounts of ascitic fluid-owing to dilatation of the mesenteric plexus and hypotension. This can be avoided by a tight binder and incomplete evacuation of liquid and air.

Laparoscopy is an extraordinarily useful procedure as well as a very safe, painless, and economical endoscopic method. By keeping it simple as it has been since Ruddock's instrument became available more than 35 years ago' it will continue to serve its purposes faithfully and safely. ${ }^{2}-\mathrm{I}$ am, etc., University of San Carlos,

RODOLFO HERRERA-LLERANDI

'Ruddock, J. C., Western fournal of Surgery, Obstetrics Herrera-Llerandi, R., British Medical fournal, 1961, 2,661 .

\section{General Practitioners and Medical Television}

SIR,-It is disappointing to find that Dr. C. M. Fletcher and Dr. R. Ll. Meyrick (13 March, p. 607) regard the content and conclusions of our paper "General Practitioners and Medical Television" (13 February, p. 392) as destructive criticism of this form of post- graduate education. This was certainly not our intention as careful scrutiny of our results would have revealed.

In comparison with previous biased studies our (validated) random sample contained a very high proportion of regular viewers who appreciated the topics dealt with in the programmes and their relevance to general practice. We intentionally did not differentiate between Independent Television and the B.B.C. except so far as advance publicity was concerned. Drs. Fletcher and Meyrick have misread our findings in this section. We said that $67 \%$ of our sample knew of I.T.V. programmes only, $4 \%$ of B.B.C. only, but $26 \%$ of both-a total of $30 \%$ for the B.B.C.

Rather than ignoring other forms of postgraduate experience one of our major objectives was to relate individual patterns of more conventional education to medical televiewing. Our results show that the enthusiastic televiewer is likely to be equally enthusiastic about clinical assistantships, medical journals, refresher courses, and other forms of continuing education.

An obvious conclusion, therefore, is that medical television reaches those doctors already stimulated in other ways, and we suggested that programmes aimed at groups meeting in postgraduate centres might be more effective than when the solitary doctor at home is the target. We are delighted that 30 of these groups report regularly to A.S.M.E. but they cannot be regarded as unbiased for this very reason. Equally we are intrigued by the certainty of your correspondents' belief in the existence of groups of which they have not yet heard. (Is this statistically significant ?)

Our ultimate question was whether available television time was being put to the most effective use. We proposed a national or regional curriculum of short provocative programmes directed towards doctors in postgraduate centres, and, in addition, because health education of the public might be more profitable, more programmes on smoking, obesity, accidents, exercise, and so on aimed at the patient rather than the profession.-We are, etc.,

J. H. WALKER J. R. THORNHAM C. S. TOWNSEND

Department of Family and

Unversity of Newcastle upon Tyne is the preventing of pressure on the calves and soles.

There is no need for a special pad which may be bulky and possibly expensive. Either a small flat sandbag or the Langton Hewer 